PERCEPCIÓN DEL IMPACTO DE LA APLICACIÓN DE MECANISMOS DE ASEGURAMIENTO DE LA CALIDAD EN LA EDUCACIÓN SUPERIOR EN COSTA RICA: PROYECTO ALFA-CINDAUNIVERSIDAD DE COSTA RICA

PERCEIVED IMPACT OF QUALITY ASSURANCE MECHANISMS ON COSTA-RICAN HIGHER EDUCATION: THE ALFA-CINDA-UNIVERSIDAD-DE-COSTA-RICA PROJECT

\author{
Volumen 12, Número 2 \\ Mayo-Agosto \\ pp. 1-38
}

Este número se publicó el 30 de mayo de 2012

Elsiana Guido Guido

Libia Herrero Uribe

Revista indizada en REDALYC

Revista distribuida en las bases de datos:

CATÁLOGO DE LATINDEX, IRESIE, CLASE, DIALNET, DOAJ, E-REVIST@S,

Revista registrada en los directorios:

ULRICH'S, REDIE, RINACE, OEI, MAESTROTECA, PREAL, HUASCARAN, CLASCO 


\title{
PERCEPCIÓN DEL IMPACTO DE LA APLICACIÓN DE MECANISMOS DE ASEGURAMIENTO DE LA CALIDAD EN LA EDUCACIÓN SUPERIOR EN COSTA RICA: PROYECTO ALFA-CINDA-UNIVERSIDAD DE COSTA RICA PERCEIVED IMPACT OF QUALITY ASSURANCE MECHANISMS ON COSTA-RICAN HIGHER EDUCATION: THE ALFA-CINDA-UNIVERSIDAD-DE-COSTA-RICA PROJECT
}

\author{
Elsiana Guido Guido \\ Libia Herrero Uribe ${ }^{2}$
}

\begin{abstract}
Resumen: En este artículo se presentan las acciones realizadas dentro del Proyecto Alfa Nro. DCl-ALA 2008/42: Aseguramiento de la calidad: políticas públicas y gestión universitaria financiado con fondos de la Unión Europea y coordinado, de manera general, por el Centro Interuniversitario de Desarrollo, CINDA. Participan 16 universidades latinoamericanas y 7 universidades europeas, y el objetivo general del proyecto es mejorar la gestión de la calidad de la Educación Superior, tanto a nivel de los sistemas nacionales como de las instituciones de Educación Superior, y contribuir con la generación de conocimiento y confianzas mutuas acerca de la calidad de la Educación Superior entre los países latinoamericanos y europeos. Como parte de las actividades desarrolladas se llevaron a cabo estudios en 7 países ( 5 de Latinoamérica y 2 de Europa) para evaluar el impacto de los procesos de aseguramiento de la calidad implementados en las universidades. En Costa Rica, el proyecto ha sido coordinado y ejecutado por la Universidad de Costa Rica desde el año 2009 hasta la fecha. El estudio se realizó en dos universidades estatales y dos privadas, durante el período comprendido entre octubre de 2010 y mayo de 2011, se realizaron 26 entrevistas presenciales y 8 sesiones de grupo a las diferentes poblaciones definidas en el estudio, además, se realizaron un total de 652 encuestas a estudiantes activos y a personas egresadas. Los principales resultados obtenidos en Costa Rica se resumen en este artículo, de acuerdo con los niveles y dimensiones de calidad que fueron definidos en el marco referencial del proyecto.
\end{abstract}

Palabras clave: MECANISMOS DE ASEGURAMIENTO DE LA CALIDAD, UNIVERSIDADES, CALIDAD, UNIVERSIDAD DE COSTA RICA, PROYECTO ALFA-CINDA, EDUCACIÓN SUPERIOR.

\begin{abstract}
The article presents actions carried out in Costa Rica, in the frame of the project Alfa Nro. DCl-ALA 2008/42: Quality assurance: public policies and management in universities. This project is funded by the European Commission and its general coordination is in charge of the Inter-university Center for Development (CINDA), in Chile. The Costa-Rican component has been coordinated and carried out by the Universidad de Costa Rica (UCR) since 2009. Sixteen Latin-American and seven European universities are participating in this project. Its general objective is to improve the quality management of higher education both on the national level, and on the individual level of each institution, as well as to generate acquaintances and mutual trust among LatinAmerican and European countries regarding the quality of their higher education. As a part of the activities of the project, 7 studies were made in 5 Latin-American and 2 European countries to evaluate the impact of the quality assurance processes that have been implemented in their universities. In Costa Rica, the study considered two state universities and two private ones. There, 26 interviews and 8 group sessions were carried out from October 2010 to May 2011 with the populations of interest for the study. Additionally, 652 active students and graduates from accredited careers of the selected universities were interviewed. A summary of the main results from the qualitative and quantitative interviews made in Costa Rica, are presented in this article
\end{abstract}

Key words: QUALITY ASSURANCE MECHANISMS, UNIVERSITY, QUALITY, UNIVERSITY OF COSTA RICA, PROJECT ALFA-CINDA. HIGHER EDUCATION.

\footnotetext{
1 Politóloga y Administradora de programas educativos no formales, Bachiller en Ciencias Políticas y Licenciada en Administración de programas educativos no formales, Universidad de Costa Rica. Investigadora del Departamento de Investigación y Evaluación Académica (DIEA) del Centro de Evaluación Académica (CEA) de la Universidad de Costa Rica. Dirección electrónica: elsiana.guido@ucr.ac.cr

${ }^{2}$ Doctora en Virología, Universidad de Londres, Inglaterra. Docente de la Cátedra de Virología Médica, Investigadora del Centro de Investigaciones en Enfermedades Tropicales, Facultad de Microbiología. Fungió como Vicerrectora de Docencia de la Universidad de Costa Rica periodo 2004-2012. Dirección electrónica: libia.herrero@ucr.ac.cr
}

Artículo recibido: 16 de setiembre, 2011

Aprobado: 17 de mayo, 2012 


\section{Introducción}

La Vicerrectoría de Docencia de la Universidad de Costa Rica coordinó, a nivel nacional, la ejecución del proyecto: Aseguramiento de la calidad: políticas públicas y gestión universitaria. Este proyecto, financiado con fondos de la Unión Europea, fue coordinado, de manera general, por el Centro Interuniversitario de Desarrollo, CINDA, que es una corporación internacional sin fines de lucro, integrada por universidades latinoamericanas y europeas, cuya sede se encuentra en la ciudad de Santiago de Chile. La Universidad de Costa Rica, al ser miembro de CINDA, fue llamada a participar en el diseño y ejecución de este proyecto en el que participaron en total 23 universidades latinoamericanas y europeas, tal y como se señala en el Cuadro $\mathrm{N}^{\circ} 1$.

Además del listado de instituciones de Educación Superior presentado en el Cuadro No.1, en este proyecto internacional se contó con la participación de la Universidad de Lima, Perú; la Pontificia Universidad Católica de Chile y la Universidad de Barcelona, España, instituciones que participaron como socias del proyecto, pero autofinanciadas, lo que significa que pagaron todos los costos asociados a su participación.

\section{Cuadro $\mathrm{N}^{\circ} 1$}

Universidades participantes en el proyecto ALFA Nro. DCI-ALA 2008/42 Aseguramiento de la calidad: políticas públicas y gestión universitaria

\begin{tabular}{ll}
\hline \multicolumn{1}{c}{ Universidad } & \multicolumn{1}{c}{ País } \\
\hline 1. Universidad Nacional de Quilmes & Argentina \\
2. Universidad Privada de Santa Cruz de la Sierra & Bolivia \\
3. Université Catholique de Louvain & Bélgica \\
4. Universidade de Sao Paulo & Brasil \\
5. Universidad Estadual de Campinas & Brasil \\
6. Universidad de los Andes & Colombia \\
7. Pontificia Universidad Javeriana & Colombia \\
8. Universidad de Costa Rica & Costa Rica \\
9. Pontificia Universidad Católica de Valparaíso & Chile \\
10. Escuela Superior Politécnica del Litoral & Ecuador \\
11. Universitat Politécnica de Catalunya & España \\
12. Universidad Santiago de Compostela & España \\
13. Universitat Oberta de Catalunya & España \\
14. Universitá degli Studi di Genova & Italia \\
15. Universidad Autónoma Metropolitana & México \\
16. Universidad de Panamá & Panamá \\
17. Universidad Católica Nuestra Señora de la Asunción & Paraguay \\
18. Pontificia Universidad Católica del Perú & Perú \\
19. Universidad Peruana Cayetano Heredia & Perú \\
20. Universidad de Aveiro & Portugal \\
21. Instituto Superior Técnico & Portugal \\
22. Universidad Católica de Uruguay & Uruguay \\
23. Universidad Simón Bolívar & Venezuela \\
\hline
\end{tabular}

Fuente: Elaboración propia 
Parte de la riqueza intercultural de este proyecto es que se tuvo la asesoría y el acompañamiento de organismos internacionales, tales como: la Red Iberoamericana para la Acreditación de la Calidad de la Educación Superior, RIACES, la International Network for Quality Assurance Agencies in Higher Education, INQAAHE y el Centre International d'Etudes Pedagogiques, CIEP.

Como objetivo general del proyecto se definió mejorar la gestión de calidad de la Educación Superior, tanto a nivel de los sistemas nacionales como de las instituciones de Educación Superior, y contribuir con la generación de conocimiento y confianzas mutuas acerca de la calidad de la Educación Superior entre los países latinoamericanos y europeos. Específicamente en el proyecto interesaba conocer acerca de la eficacia y pertinencia relativas de los distintos mecanismos utilizados para asegurar y mejorar la calidad de la Educación Superior en América Latina; contribuir con el diseño de políticas públicas tendientes a mejorar la gestión de la calidad de la Educación Superior y desarrollar capacidades entre los distintos actores vinculados con el aseguramiento de la calidad, considerando, principalmente, a quienes toman decisiones de política, a quienes administran los procesos externos de evaluación y acreditación y a quienes administran los procesos internos de aseguramiento de la calidad en las instituciones de Educación Superior (Centro Interuniversitario de Desarrollo, 2008, p. 10).

Con la ejecución del proyecto se esperaba contar con una metodología para evaluar el impacto de los procesos de aseguramiento de la calidad instalados en los respectivos países, que pudiera ser aplicada en el mediano y largo plazo por los demás países; se quería, también, evaluar el impacto de los mecanismos de aseguramiento de la calidad aplicados en los países participantes y brindar recomendaciones de política relativas a la gestión de calidad de la Educación Superior. Otro de los grandes objetivos del proyecto fue diseñar unos módulos para la formación y capacitación en temas relacionados con el aseguramiento de la calidad, dirigidos a personas de las universidades como de las agencias de acreditación e instituciones de Educación Superior (Centro Interuniversitario de Desarrollo, 2008, pp. 9-10).

El proyecto consta, entonces, de dos partes o líneas de acción: una destinada a evaluar el impacto de los procesos de aseguramiento de la calidad, y otra cuyo objeto es la elaboración, desarrollo y aplicación experimental de un conjunto de módulos de formación para el aseguramiento de la calidad, dirigidos hacia los principales actores involucrados en 
dichos procesos. La Universidad de Costa Rica participó en ambas líneas de acción; sin embargo, en este artículo se exponen la metodología, el desarrollo del estudio, así como los principales resultados de la primera línea de acción descrita. Para tal fin, en un primer apartado se explica el procedimiento metodológico seguido en el proyecto y en el desarrollo del estudio; seguidamente, se exponen los principales referentes conceptuales que fueron construidos de manera colectiva por todas las universidades participantes en el proyecto ALFA, que sirvieron para la ejecución de las actividades y el análisis de los datos recogidos $y$, finalmente, en un tercer apartado se presentan, de manera general, los principales hallazgos obtenidos en el estudio realizado en Costa Rica, los que se muestran obviando las especificidades propias de cada una de las universidades participantes.

\section{Procedimiento metodológico}

Para el desarrollo de la línea de acción referida a la evaluación del impacto de los procesos de aseguramiento de la calidad, en el proyecto: Aseguramiento de la calidad: políticas públicas y gestión universitaria se siguieron los siguientes pasos metodológicos:

- Se desarrolló un marco de referencia donde se definió el concepto de calidad que se iba a utilizar en la investigación y se establecieron indicadores cualitativos y cuantitativos.

- Se redactaron informes nacionales sobre los sistemas de Educación Superior y los procesos de aseguramiento de la calidad en los países participantes en el proyecto. En estos informes se describieron, de manera detallada, las características y funcionamiento de los distintos mecanismos de aseguramiento de la calidad vigentes en cada país, lo que permitió delimitar y particularizar cada sistema y establecer un marco de referencia sobre el contexto en el que se desarrollan dichos procesos en el sistema de Educación Superior de cada uno de los países participantes en el proyecto.

- Se identificaron las dimensiones para la medición de impacto del aseguramiento de la calidad de la gestión institucional y la docencia.

- Se diseñaron instrumentos para efectuar la medición de impacto en cada uno de los países donde se realizó el estudio.

- Se validaron los instrumentos para la recolección de la información así como el procedimiento, en una prueba piloto.

- Se aplicaron los instrumentos en los siete países participantes. 
- Se sistematizaron los resultados y recomendaciones de política. (Proyecto ALFA III: Aseguramiento de la calidad: políticas públicas y gestión universitaria, 2011, junio).

Una vez definido lo anterior, el grupo de universidades participantes, en conjunto con la coordinación general del proyecto, definieron los criterios para la elección de los países en los que se desarrollaría esta línea de acción, o sea, se definieron las características que debían poseer los sistemas de Educación Superior y los mecanismos de aseguramiento de la calidad en los países donde se iba a realizar el estudio del impacto de los procesos de aseguramiento de la calidad. Los criterios para la elección de los países fueron, entonces, los siguientes:

- Que los países tuvieran una agencia a cargo de los procesos de aseguramiento de la calidad.

- Que los países hubieran desarrollado procesos de aseguramiento de la calidad en un número significativo de instituciones de educción superior y de programas educativos.

- Que dichos procesos hayan estado vigentes durante un mínimo de cinco años. (Proyecto ALFA III: Aseguramiento de la calidad: políticas públicas y gestión universitaria, 2011, junio).

De acuerdo con los criterios definidos fueron elegidos siete países donde se realizó el estudio de impacto, cinco de Latinoamérica y dos de Europa, a saber: Argentina, Chile, Colombia, Costa Rica, España, México y Portugal.

Cada representante de las universidades participantes en el proyecto se desempeñó como coordinador (a) nacional para la ejecución del estudio; esta persona tuvo a su cargo la selección de las cuatro universidades que participarían en la investigación en cada país, en el caso de México, dado el tamaño y la complejidad de su sistema educativo, el estudio se realizó en seis universidades. Las coordinaciones nacionales debían asegurarse que la investigación se desarrollara en el plazo y las condiciones de calidad y rigurosidad acordadas.

También, en el proyecto se establecieron criterios para la selección de las universidades, de cada uno de los siete países seleccionados, que participarían en la investigación; los criterios seleccionados buscaban que en la investigación se incluyeran tanto a universidades públicas como a universidades privadas, a universidades 
metropolitanas y a universidades regionales. Adicionalmente, se estableció como un requisito que las universidades seleccionadas tuvieran procesos de aseguramiento de la calidad consolidados, de acuerdo con los parámetros definidos en el proyecto.

En el caso de Costa Rica, la investigación se realizó en la Universidad de Costa Rica, (UCR) sede Rodrigo Facio, en el Instituto Tecnológico de Costa Rica (ITCR), sede de la provincia de Cartago, en la Universidad Latina, Campus Heredia (U.Latina) y en la Universidad Veritas (U.Veritas). Las dos primeras son universidades estatales y las dos segundas son universidades privadas.

El proceso de recolección de la información tuvo dos fases. En una fase cualitativa se realizaron veintiséis entrevistas presenciales y ocho sesiones de grupo a los diferentes actores definidos en el estudio, tal y como se desglosa en el Cuadro $\mathrm{N}^{\circ} 2$. Las pautas para las entrevistas y los grupos focales fueron brindadas por el proyecto, así como validadas en una prueba piloto, de manera tal que en todos los siete países participantes se aplicaron los mismos instrumentos, con el objetivo de garantizar algún grado de comparabilidad en los análisis posteriores.

\section{Cuadro $\mathbf{N}^{\circ} 2$}

Proyecto ALFA-CINDA: Aseguramiento de la calidad: políticas públicas y gestión universitaria. Entrevistas realizadas en Costa Rica, según actores

\begin{tabular}{|c|c|c|}
\hline Actores & Institución de Educación Superior & Cantidad \\
\hline $\begin{array}{l}\text { Vicerrectores (as) } \\
\text { Académicos }\end{array}$ & $\begin{array}{l}\text { 1. Vicerrectoría de Docencia, UCR } \\
\text { 2. Vicerrectoría de Docencia, ITCR } \\
\text { 3. Vicerrectoría Académica, U. Latina. } \\
\text { 4. Vicepresidencia Ejecutiva, U. Veritas }\end{array}$ & $\mathrm{n}=4$ \\
\hline $\begin{array}{l}\text { Directores (as) de } \\
\text { Planificación }\end{array}$ & $\begin{array}{l}\text { 5. Dirección, Oficina de Planificación Universitaria, UCR } \\
\text { 6. Dirección, Oficina de Planificación Institucional, ITCR } \\
\text { 7. Dirección de Planificación Financiera, U.Latina Campus } \\
\text { Heredia }\end{array}$ & $\mathrm{n}=3$ \\
\hline Autoridades de Facultad & $\begin{array}{l}\text { 8. Decanatura de Ciencias Básicas, UCR } \\
\text { 9. Decanatura de Facultad de Ingeniería y Arquitectura, } \\
\text { U.Latina Campus Heredia } \\
\text { 10. Decanatura de Excelencia e Innovación Académica, } \\
\text { U.Veritas } \\
\text { 11. Decanatura de la Facultad de Diseño, U.Veritas }\end{array}$ & $\mathrm{n}=4$ \\
\hline Autoridades de Carrera & $\begin{array}{l}\text { 12. Dirección de la Escuela de Ciencias de la Comunicación } \\
\text { Colectiva, UCR } \\
\text { 13. Dirección de la Escuela de Administración de Empresas, } \\
\text { ITCR } \\
\text { 14. Dirección de la Escuela de Ingeniería Industrial, U.Latina, } \\
\text { Campus Heredia } \\
\text { 15. Dirección de la Escuela de Arquitectura, U.Veritas }\end{array}$ & $\mathrm{n}=4$ \\
\hline $\begin{array}{l}\text { Encargados (as) del } \\
\text { Aseguramiento de la } \\
\text { Calidad (AQ) }\end{array}$ & $\begin{array}{l}\text { 16. Jefatura del Departamento de Investigación y Evaluación } \\
\text { Académica del Centro de Evaluación Académica (CEA), } \\
\text { UCR }\end{array}$ & $\mathrm{n}=4$ \\
\hline
\end{tabular}




\begin{tabular}{|c|c|c|}
\hline Actores & Institución de Educación Superior & Cantidad \\
\hline & $\begin{array}{l}\text { 17. Dirección del Centro de Desarrollo Académico (CEDA), } \\
\text { ITCR } \\
\text { 18. Unidad Encargada de Aseguramiento de la Calidad } \\
\text { Académica y Docente(ASCAD), U.Latina, Campus Heredia } \\
\text { 19. Dirección de Calidad Académica, U.Veritas }\end{array}$ & \\
\hline \multirow[t]{4}{*}{ Docentes } & $\begin{array}{l}\text { 20. Escuelas, UCR: Trabajo Social, Biología, Medicina, } \\
\text { Educación Física, Agronomía, Farmacia, Psicología }\end{array}$ & $\begin{array}{l}\mathrm{n}=7 \text { carreras, } \\
9 \text { docentes }\end{array}$ \\
\hline & $\begin{array}{l}\text { 21. Escuelas, ITCR: Ingeniería Forestal, Ingeniería en } \\
\text { Agronomía, Ingeniería en Biotecnología, Ingeniería en } \\
\text { Computación, Matemática }\end{array}$ & $\begin{array}{l}n=5 \text { carreras, } \\
5 \text { docentes }\end{array}$ \\
\hline & $\begin{array}{l}\text { 22. Escuelas, U.Latina Campus Heredia: Administración de } \\
\text { Negocios, Relaciones Públicas, Ingeniería de Sistemas, } \\
\text { Ingeniería Industrial }\end{array}$ & $\begin{array}{l}\mathrm{n}=4 \text { carreras, } \\
11 \text { docentes }\end{array}$ \\
\hline & $\begin{array}{l}\text { 23. Escuelas, U.Veritas: Diseño Publicitario, Arquitectura, } \\
\text { Diseño del Espacio Interno }\end{array}$ & $\begin{array}{l}n=3 \text { carreras, } \\
14 \text { docentes }\end{array}$ \\
\hline $\begin{array}{l}\text { Directivo de Agencia } \\
\text { Nacional de } \\
\text { Aseguramiento de la } \\
\text { Calidad }\end{array}$ & $\begin{array}{l}\text { 24. Presidencia del Consejo Nacional de Acreditación de la } \\
\text { Educación Superior (SINAES). }\end{array}$ & $\mathrm{n}=1$ \\
\hline Autoridad Gubernamental & $\begin{array}{l}\text { 25. Dirección de la Oficina de Planificación de la Educación } \\
\text { Superior (OPES) }\end{array}$ & $N=1$ \\
\hline $\begin{array}{l}\text { Asociaciones } \\
\text { Profesionales }\end{array}$ & $\begin{array}{l}\text { 26. Presidencia del Colegio de Ingenieros Tecnólogos (CITEC) } \\
\text { 27. Presidencia del Colegio de Médicos } \\
\text { 28. Presidencia del Colegio de Periodistas y Comunicadores de } \\
\text { Costa Rica } \\
\text { 29. Presidencia del Colegio de Ciencias Económicas } \\
\text { 30. Presidencia de la Asociación Costarricense de Agencias de } \\
\text { Publicidad (ASCAP). }\end{array}$ & $N=5$ \\
\hline
\end{tabular}

Fuente: Proyecto Alfa Nro. DCl-ALA 2008/42. Aseguramiento de la Calidad: políticas públicas y gestión universitaria. (2011a). Informe de Evaluación de impacto de los mecanismos de aseguramiento de la calidad en la Educación Superior-Costa Rica. Costa Rica.

El estudio tuvo también una fase cuantitativa en la que se entrevistó a estudiantes activos y a personas egresadas, ambas poblaciones provenientes de carreras acreditadas de las universidades seleccionadas. En total se realizaron 652 entrevistas distribuidas tal y como se indica en el cuadro $\mathrm{N}^{\circ} 3$. A la población estudiantil se le pasó un cuestionario autoaplicado en situación grupal, que, al 95\% de confianza, arroja un margen de error en las mediciones de $+-4.6 \%$. A los egresados y egresadas de las carreras se les consultó por medio de una encuesta en línea, en total respondieron 200 personas, lo que da un margen de error del +-6.9\% al 95\% de confianza. 


\section{Cuadro $\mathrm{N}^{\circ} 3$}

Proyecto ALFA-CINDA: Aseguramiento de la calidad: políticas públicas y gestión universitaria. Distribución de las entrevistas realizadas a estudiantes y personas egresadas, según actores y universidad participante

\begin{tabular}{lccc}
\hline \multicolumn{1}{c}{ Universidad } & \multicolumn{2}{c}{ Entrevistas realizadas } & Total de personas consultadas \\
\cline { 2 - 3 } & Estudiantes & Egresados (as) & 218 \\
UCR & 150 & 68 & 150 \\
U. Veritas & 123 & 27 & 146 \\
U. Latina & 98 & 48 & 138 \\
ITCR & 81 & 57 & 652 \\
Total & 452 & 200 & Elaboración propia con base en Proyecto Alfa Nro. DCl-ALA 2008/42. Aseguramiento de la Calidad: políticas \\
públicas y gestión universitaria. (2011a). Informe de Evaluación de impacto de los mecanismos de aseguramiento \\
de la calidad en la Educación Superior- Costa Rica. Costa Rica.
\end{tabular}

\section{Marco de referencia}

En el proyecto se definió un marco teórico de referencia que permitió orientar el estudio, definir algunos conceptos medulares para el desarrollo de la investigación así como establecer las dimensiones en las cuales se exploraría y analizaría el concepto de calidad.

En el marco referencial del proyecto se deja claro que los hallazgos que se obtengan del estudio deberán de ser analizados de acuerdo con las características de cada país; en este sentido, se menciona que el análisis se deberá hacer

dentro del marco de los propósitos de los procesos de aseguramiento de la calidad vigentes en los distintos países participantes, ya que éstos constituyen la "variable independiente", es decir, los factores que condicionan el efecto que se espera poder observar en los respectivos sistemas de Educación Superior o sus instituciones. (Proyecto Alfa Nro. DCl-ALA 2008/42. Aseguramiento de la Calidad: políticas públicas y gestión universitaria, 2009b, p. 1)

En su marco referencial, el proyecto dejó clara la dificultad de establecer relaciones de causalidad entre la aplicación de determinados mecanismos de aseguramiento de la calidad y los cambios que se pudieran observar, percibir o detectar en las universidades participantes. De este modo, con los resultados obtenidos en el estudio realizado en Costa Rica

No se pretende establecer relaciones causales entre los procesos de aseguramiento de la calidad y los cambios relativos a la calidad en las instituciones de Educación 
Superior. Sabemos que es prácticamente imposible aislar el efecto que dichos procesos pudieran tener sobre la acción de las instituciones de Educación Superior. Sin embargo, esperamos demostrar que la instalación e implementación de procesos y mecanismos de aseguramiento de la calidad tienden a ir acompañados de ciertos cambios en las instituciones, e intentaremos verificar si es posible considerar que esos cambios constituyen un impacto (positivo o negativo) sobre la calidad de la oferta educativa. (Proyecto Alfa Nro. DCl-ALA 2008/42. Aseguramiento de la Calidad: políticas públicas y gestión universitaria, 2009b, p. 1)

Dos conceptos son importantes dentro del marco referencial del proyecto: por un lado, definir qué se entiende por mecanismos de aseguramiento de la calidad y, por otra parte, definir y operacionalizar el concepto de calidad y establecer las dimensiones de calidad que se proponen para la medición del impacto de los procesos de aseguramiento de la calidad. Con respecto al primero, en el proyecto se siguen los planteamientos de Vlãsceanu et al., 2004, donde los mecanismos de aseguramiento de la calidad pueden estar orientados al control, a la garantía o al mejoramiento de la calidad de las instituciones de Educación Superior y se entienden como

Un proceso permanente y continuo de evaluación de la calidad de un sistema, instituciones o programas de Educación Superior. Por evaluación en este caso, se entiende evaluación propiamente tal, así como monitoreo, garantía, mantención y mejora de estos niveles. En cuanto mecanismo regulatorio, el aseguramiento de la calidad contempla tanto la rendición de cuentas (accountability) como el mejoramiento, mediante la provisión de información y juicios, a través de un proceso concordado y consistente y de criterios claramente establecidos. (Proyecto Alfa Nro. DCl-ALA 2008/42. Aseguramiento de la Calidad: políticas públicas y gestión universitaria, 2009b, p. 13)

En lo que se refiere al concepto de calidad, en el proyecto se acogió una definición de calidad que lejos de pretender ser única, es operacional en el sentido de facilitar el desarrollo de la investigación. El concepto de calidad adquiere aquí una connotación "integral”, esto significa que se considera la consistencia entre los distintos factores internos y externos que componen una institución de Educación Superior. Es así como se optó por la siguiente 
definición de calidad, que permite hasta cierto punto ser operacionalizada para los efectos del estudio

Calidad en la Educación Superior puede ser definida como el grado de ajuste entre las acciones que una institución, programa académico o carrera pone en marcha para dar cumplimiento a las orientaciones emanadas desde su misión y propósitos institucionales y los resultados que de estas acciones obtiene. (Proyecto Alfa Nro. DClALA 2008/42. Aseguramiento de la Calidad: políticas públicas y gestión universitaria, 2009b, p. 6)

La definición de los propósitos institucionales debe contemplar dos dimensiones, para que la definición anterior de calidad no sea totalmente autorreferente: una que se refiere a la consistencia externa y otra a la consistencia interna. La consistencia externa de los propósitos institucionales hace referencia al

ajuste a las exigencias del medio externo (entendiendo por éste el grupo de referencia institucional, disciplinario, profesional o tecnológico correspondiente), que se materializan en demandas provenientes del mercado laboral, la comunidad académica, o el entorno socio económico particular de cada IES. La consistencia externa asegura la pertinencia de los propósitos y permite la comparabilidad entre instituciones y programas. (Proyecto Alfa Nro. DCl-ALA 2008/42. Aseguramiento de la Calidad: políticas públicas y gestión universitaria, 2009b, p. 6)

Por su lado, la consistencia interna de los propósitos institucionales se refiere a la manera en que la institución educativa traduce las exigencias externas descritas tomando en consideración las prioridades y los principios de la universidad

Esta dimensión permite desplegar la capacidad propositiva de la universidad, y ampliar el rango de ofertas posibles en el sistema de Educación Superior, asegurando así una oferta diversa, que busque dar una respuesta amplia a las necesidades sociales. (Proyecto Alfa Nro. DCl-ALA 2008/42. Aseguramiento de la Calidad: políticas públicas y gestión universitaria, 2009b, p. 6)

Es importante mencionar que en el estudio no se visualizan relaciones lineales ni unidireccionales entre los elementos descritos, ya que se reconoce que 
para poder definir calidad se debe caracterizar adecuadamente cada uno de los elementos que componen el sistema universitario, es decir actores, procesos, recursos y resultados. Esto significa poder describir estas componentes institucionales en términos de factores que afectan o influyen sobre la calidad global de los productos académicos de una determinada institución, carrera o programa, y las relaciones que en un determinado contexto se establecen. (Proyecto Alfa Nro. DCl-ALA 2008/42. Aseguramiento de la Calidad: políticas públicas y gestión universitaria, 2009b, p. 7)

En el esquema $N^{\circ} 1$ se visualizan los factores que intervienen en la calidad de una institución de Educación Superior así como las relaciones que se establecen entre los componentes, tal y como se definió en el proyecto.

\section{Esquema $\mathrm{N}^{\circ} 1$}

Proyecto Alfa Nro. DCl-ALA 2008/42: Aseguramiento de la calidad: políticas públicas y gestión universitaria. Factores que intervienen en la calidad de una institución de Educación Superior

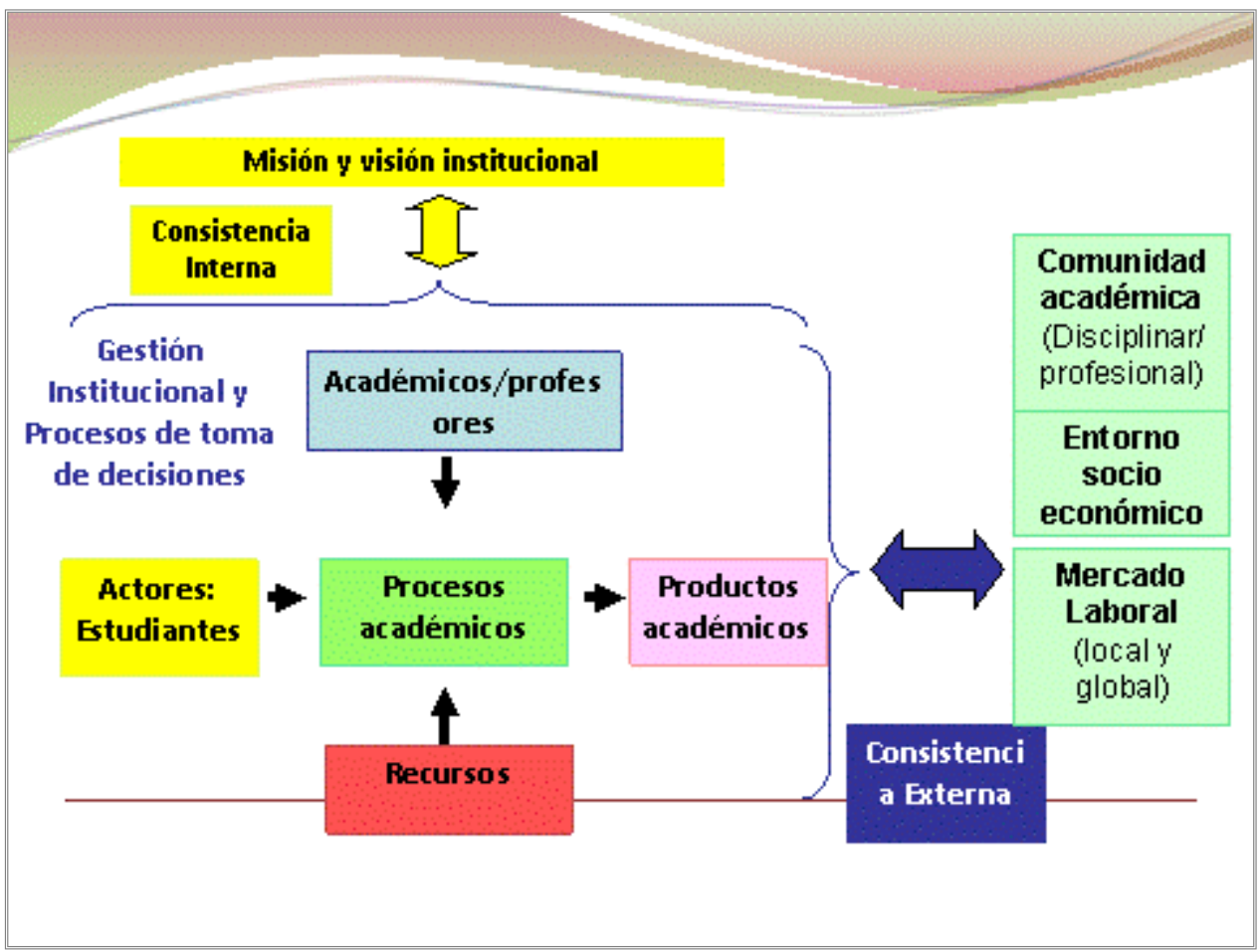

Tomado de: Proyecto Alfa Nro. DCl-ALA 2008/42. Aseguramiento de la Calidad: políticas públicas y gestión universitaria, 2009b, p. 7. 
Para finalizar este apartado, es importante hacer referencia a las dimensiones de calidad para la medición del impacto de los procesos de aseguramiento de la calidad, identificadas en el marco del proyecto. En total se identificaron 18 dimensiones las que se clasificaron en tres niveles, a saber: sistemas de Educación Superior, gestión institucional y docencia.

En el cuadro $\mathrm{N}^{\circ} 4$ se resumen los niveles y las respectivas dimensiones identificadas.

\section{Cuadro $\mathrm{N}^{\circ} 4$}

Proyecto Alfa Nro. DCl-ALA 2008/42: Aseguramiento de la calidad: políticas públicas y gestión universitaria. Niveles y dimensiones de calidad

\begin{tabular}{|c|c|}
\hline Nivel & Dimensión \\
\hline $\begin{array}{l}\text { I. Sistemas de Educación } \\
\text { Superior }\end{array}$ & $\begin{array}{l}\text { 1. Institucionalización del trabajo de aseguramiento de la calidad } \\
\text { 2. Información sobre el sistema de Educación Superior }\end{array}$ \\
\hline & $\begin{array}{l}\text { 3. Conciencia pública } \\
\text { /marketing }\end{array}$ \\
\hline
\end{tabular}

II. Gestión institucional

4. Internacionalización del tema de la calidad

III. Docencia

1. Instalación de mecanismos/procesos de aseguramiento de la calidad

2. Desarrollo de sistemas de información

3. Gestión, gobierno y administración de las instituciones de Educación Superior y sus programas

4. Gestión académica institucional

5. Gestión administrativa y financiera

6. Participación de actores internos y externos en los procesos de aseguramiento de la calidad. Generación de una cultura de calidad

7. Redefinición de las funciones universitarias (cambios en el peso relativo)

2. Análisis de información sobre progresión y logros

3. Evaluación de resultados de aprendizaje

4. Formación pedagógica de los docentes

5. Estrategias pedagógicas

6. Cambios en la evolución de académicos

7. Responsabilidad institucional por los resultados del proceso de enseñanza y aprendizaje

Fuente: Elaboración propia con base en Proyecto Alfa Nro. DCl-ALA 2008/42. Aseguramiento de la Calidad: políticas públicas y gestión universitaria, s.f., pp. 1- 11 .

\section{Hallazgos obtenidos en Costa Rica}

Los principales hallazgos obtenidos se organizan siguiendo los niveles y las dimensiones anteriormente descritas; los resultados se presentarán de manera general y solo en casos específicos se diferenciará entre las universidades. Se considera importante 
presentar antes, una breve contextualización y caracterización del sistema de educación y del sistema de aseguramiento de la calidad de Costa Rica.

\section{Breve contextualización y caracterización del sistema de educación y del sistema de aseguramiento de la calidad de Costa Rica}

La historia de la Educación Superior en Costa Rica se remonta a siete décadas atrás, cuando en 1941 se fundó la Universidad de Costa Rica ${ }^{3}$. Las décadas de los setenta y los ochenta se caracterizaron por la creación de nuevos centros de Educación Superior, tanto públicos como privados. En los años setenta, el Estado costarricense creó otras tres universidades: el Instituto Tecnológico de Costa Rica (1971), la Universidad Nacional (1973) y la Universidad Estatal a Distancia (1977). Más recientemente, en el año 2008, se creó la Universidad Técnica Nacional de Costa Rica, como la quinta universidad estatal. (Proyecto Alfa Nro. DCl-ALA 2008/42 Aseguramiento de la Calidad: políticas públicas y gestión universitaria, 2009a, p.9).

El país tiene, además, una amplia oferta de Educación Superior privada: a la fecha se cuenta con 51 centros educativos de naturaleza privada que ofrecen programas académicos. Según datos de Tercer Informe del Estado de la Educación (2011), en el año 2009, un 6.4\% de la población nacional reportó que asistía a la Educación Superior y, entre las personas de 18 a 24 años, la asistencia alcanzó un 25.8\% (p. 42).

Las Universidades estatales no son reguladas por ninguna institución o ente gubernamental; los asuntos relativos a la ejecución presupuestaria y la contratación administrativa son fiscalizados por la Contraloría General de la República, como cualquier otra institución pública del país. Existe un órgano de coordinación de la Educación Superior estatal, el Consejo Nacional de Rectores (CONARE), creado de manera voluntaria por las universidades, que tiene los mismos privilegios de autonomía frente al Poder Ejecutivo que sus integrantes. Las universidades privadas, así como los programas académicos que imparten, se rigen por las disposiciones de la Ley del Consejo de Educación Superior Privada (CONESUP) y su reglamento, que fundamentalmente establece condiciones materiales para aprobar su funcionamiento.

\footnotetext{
3 Los primeros esfuerzos por crear un centro de Educación Superior en Costa Rica se dan en año 1843, cuando se estableció la Universidad de Santo Tomás de Costa Rica, que funcionó hasta el año1886.
} 
En Costa Rica no existe una política pública de Educación Superior para todo el sistema, esto se explica dado el nivel de autonomía que ostentan las universidades estatales y las libertades garantizadas para las universidades privadas, en un sistema de Educación Superior altamente fragmentado (Proyecto Alfa Nro. DCl-ALA 2008/42 Aseguramiento de la Calidad: políticas públicas y gestión universitaria, 2009a).

En este panorama actual, donde confluyen tantas instituciones universitarias de diversa índole y calidades, la Educación Superior presenta una serie de retos para fortalecer y ampliar su aporte al desarrollo nacional. Según el Informe del Estado de la Educación (2011), un primer desafío consiste en consolidar los espacios de interacción entre las universidades estatales y las universidades privadas con el objetivo de converger en "altos estándares de calidad' (p. 43). Un segundo desafío consiste en generar y divulgar mayor información acerca del desempeño de las universidades costarricenses, tanto en el ámbito privado, donde la información es insuficiente, como en el ámbito de la Educación Superior estatal, donde a pesar de que existen los datos debe trabajarse en la estandarización de los indicadores de desempeño. Finalmente, un tercer desafío señalado por este estudio consiste en hacer un llamado a mejorar la calidad de la oferta educativa del país y a ampliar la cantidad de carreras acreditadas, ya que, hasta el año 2010 , únicamente un $5.4 \%$ de la oferta educativa contaba con la acreditación por parte del Sistema Nacional de Acreditación de la Educación Superior (SINAES, p.43).

En cuanto al sistema de aseguramiento de la calidad, debe mencionarse que este se ha desarrollado como resultado de las necesidades y las características del sistema de Educación Superior del país. La preocupación por la calidad y la excelencia de la Educación Superior, y por las maneras en que se puede evaluar esa calidad, ha sido una constante en las universidades estatales costarricenses lo que se evidencia en una serie de iniciativas y acciones concretas desarrolladas desde mediados de los años noventa en las instituciones de Educación Superior.

Es así como, en Costa Rica, además del Sistema Nacional de Acreditación de la Educación Superior (SINAES), la agencia de acreditación oficial, existen procesos internos en las universidades, especialmente las públicas, y en algunas universidades privadas, así como en algunas instancias nacionales, regionales o extrarregionales, que de una u otra manera son parte del conjunto de mecanismos que las instituciones de Educación Superior tienen a su disposición para asegurarle al país la calidad de sus procesos y resultados 
educativos. No puede decirse que funcionen como un sistema estructurado, ni que el SINAES tenga relación con todos ellos, pero están presentes, con distintas intensidades, en el sistema de Educación Superior (Proyecto Alfa Nro. DCl-ALA 2008/42 Aseguramiento de la Calidad: políticas públicas y gestión universitaria, 2009a, pp. 39-40).

La agencia de acreditación SINAES fue creada en el año 2002 como iniciativa de las universidades estatales las que, a su vez, gozan, como ya se dijo, de autonomía para su organización. Esta es una característica distintiva del sistema costarricense de acreditación, que lo diferencia de la mayoría de las experiencias internacionales, donde generalmente el gobierno central desempeña un papel importante como rector de la educación nacional, con potestades para exigir rendición de cuentas a las instituciones que conforman el sistema nacional de educación.

Debe destacarse, también, el carácter voluntario de la acreditación y los pocos mecanismos de incentivos o estímulos para promoverla en las carreras universitarias. A la fecha, cuatro universidades estatales y siete universidades privadas son miembros plenos del SINAES, ya que han cumplido los requisitos de afiliación y mantienen vigente la acreditación oficial mínima de carreras o programas de grado. También, es importante mencionar que actualmente el SINAES ha otorgado la acreditación a 64 carreras, 25 de ellas han sido reacreditadas. Las cuatro universidades estatales más antiguas cuentan con carreras acreditadas lo mismo que siete universidades privadas y una universidad con carácter internacional.

\section{Nivel I: Sistema de Educación Superior}

\section{Institucionalización y funcionamiento del trabajo de aseguramiento de la calidad}

En esta dimensión se indagó acerca de los diferentes efectos que se pueden observar a partir de la consolidación, o de la creación, de instancias encargadas de la ejecución de las funciones asociadas al aseguramiento de la calidad en las universidades (Proyecto Alfa Nro. DCl-ALA 2008/42, s.f., p.1).

La tendencia de las universidades consultadas en Costa Rica se orienta hacia el establecimiento de procesos de aseguramiento de la calidad que favorecen las autoevaluaciones como mecanismos para la mejora constante, o para la obtención de la acreditación por parte de la agencia, por lo que, al interior de cada una de las universidades 
consultadas se han conformado instancias técnicas que funcionan de manera permanente como coordinadoras institucionales de todos estos procesos. La antigüedad de estas oficinas varía en cada universidad y sus funciones abarcan desde la asesoría para las carreras que incursionan en tales procesos de mejoramiento, hasta el acompañamiento en el proceso mismo de autoevaluación para la acreditación y en la elaboración de instrumentos y coordinación de procesos, entre otras. Se considera que estos equipos de profesionales están bien capacitados y cuentan con una formación y actualización permanente en temas relacionados con los procesos de aseguramiento de la calidad.

Adicionalmente, al interior de cada carrera que ha tenido un proceso de autoevaluación se han conformado comisiones encargadas de dirigir, coordinar y ejecutar todos los procedimientos necesarios para la autoevaluación, acreditación o re-acreditación. En muchos de los casos, tales comisiones han sido creadas como producto de los mismos procesos ante la necesidad de que existan instancias que se dediquen, de forma permanente, a orientar todas las acciones y a monitorear o darle seguimiento al proceso; generalmente estas instancias están conformadas por los y las docentes de las carreras.

En esta dimensión se destaca la creación en el año 2002 de la agencia de acreditación oficial, denominada Sistema Nacional de Acreditación de la Educación Superior (SINAES), a la que están adheridas tanto universidades públicas como privadas y sus criterios y estándares tienen carácter de norma nacional de calidad académica (SINAES, 2009, p.7). De este modo, el país cuenta con criterios mínimos y estándares para la acreditación de carreras y programas universitarios.

En general, las autoridades universitarias consultadas consideran que existe una política general institucional a favor de la acreditación y que acreditarse es importante, porque significa certificar -desde un criterio objetivo de pares externos- que se tienen los criterios mínimos necesarios de admisibilidad y de calidad.

También, se observa la tendencia a valorar, de manera positiva, las funciones y disposiciones normativas que ha establecido el SINAES, las que se considera que han ayudado a las carreras a mejorar tanto a lo interno como en lo que respecta a su proyección institucional, por ejemplo, en algunas de las universidades se destacó que los criterios normativos del SINAES han sido coincidentes con algunos de sus propios parámetros de calidad establecidos institucionalmente. Adicionalmente, se reconoce que el acatamiento de estas normas de la agencia han conllevado una mejora en los servicios administrativos, a 
soluciones en cuanto a infraestructura, actualización, beneficios a nivel de nombramientos y capacitaciones a los y las docentes, cambios en el currículum, internacionalización, entre varios de los beneficios percibidos que devienen de los compromisos de mejoramiento posteriores al proceso de acreditación o de re-acreditación.

Las personas de las universidades consultadas coinciden en que el proceso de acreditación permite no solo evidenciar las debilidades internas de las carreras en las instituciones, sino trazar planes de acción viables para ejecutar cambios hacia el fortalecimiento y mejoramiento de la educación y de los servicios que se brindan. En algunos casos, se menciona la incorporación de criterios de calidad en la creación de programas de estudio, en cambios curriculares o en la normativa institucional; en general, se menciona el fomento de prácticas culturales que propician la calidad de sus procesos y resultados académicos.

De igual forma, es importante mencionar que las personas consultadas en las Oficinas de Planificación Universitaria parecen estar muy al margen de los procesos y mecanismos asociados al aseguramiento de la calidad. Esto se vislumbra en el poco conocimiento que expresan tener sobre el funcionamiento de las agencias de acreditación, así como sobre las normas y procedimientos de los diferentes mecanismos de aseguramiento de la calidad. Las funciones de estas instancias parecen estar más vinculadas con aspectos presupuestarios posteriores al proceso que tienen las unidades académicas una vez que han sido acreditadas, es decir, con la creación de marcos estratégicos presupuestarios que valoren la viabilidad -en términos financieros- de los planes que tiene cada carrera.

\section{Información sobre el sistema de Educación Superior}

En esta dimensión se indagó acerca de las maneras en que la aplicación de mecanismos de aseguramiento de la calidad ha facilitado la recopilación y organización de la información sobre las instituciones de Educación Superior (Proyecto Alfa Nro. DCl-ALA 2008/42, s.f., p. 2). En este sentido, tanto las universidades públicas como las universidades privadas, consultadas en este estudio, coinciden en que existen sistemas de manejos de datos sobre la Educación Superior, pero estos son internos a cada institución y no son accesibles públicamente. No existe un sistema nacional que proporcione la información útil y necesaria que se requiere para la toma de decisiones sobre la gestión universitaria. 
En términos generales, las universidades participantes consideran que la información no es de acceso fácil y oportuno para aquellos actores implicados tales como padres y madres de familia, y para potenciales estudiantes, y que la información existente se comunica de manera parcial. Además, es notoria la carencia de información pública sobre el quehacer y los procesos que se realizan en las universidades privadas.

El $97 \%$ del sector estudiantil consultado en este estudio tiene conocimiento de que la carrera o programa en el que estudia actualmente, se encuentra acreditado. Sin embargo, se identifica un desconocimiento generalizado sobre la existencia de algún sistema nacional que entregue información sobre las instituciones de Educación Superior, ya que poco menos de dos terceras partes de los entrevistados (62.9\%) no conoce, o afirmó que no existe, dicho sistema.

Existe un desconocimiento generalizado, por parte de las personas egresadas consultadas, acerca de la existencia de algún sistema nacional que entregue información sobre las instituciones de Educación Superior, acerca de la calidad de las mismas, la oferta de posgrado, empleo para egresados o remuneración. Este desconocimiento se incrementa en el segmento de egresados (as) de universidades privadas.

\section{Conciencia pública sobre la calidad, relaciones públicas, marketing}

Esta dimensión definida en el proyecto se refiere a la medida en que la difusión social de los resultados de la aplicación de los mecanismos de aseguramiento de la calidad hacen más visibles los procesos de la Educación Superior y facilitan que se tome en cuenta la calidad para la toma de decisiones sobre opciones de estudio o la calidad de los egresados (Proyecto Alfa Nro. DCl-ALA 2008/42, s.f., p. 3).

De acuerdo con las percepciones encontradas en esta dimensión, la opinión general es que existe un desconocimiento público sobre lo que significa la acreditación y sus implicaciones para la sociedad; las personas entrevistadas opinan que esta información se difunde muy poco y que el SINAES debería ser más proactivo y desarrollar estrategias efectivas que permitan mejorar la divulgación.

En términos generales, los sistemas de comunicación hacia el público se valoran como muy incipientes o casi inexistentes, por lo que este aspecto lo consideran como poco desarrollado y hasta cierto punto descuidado. A pesar de esta situación, algunas personas consultadas en las universidades participantes resaltan el esfuerzo institucional que se 
realiza para comunicar, a nivel interno de cada universidad, cuando una carrera se acredita, también, intentan "mercadearse" más hacia públicos externos, no únicamente en cuanto a procesos de acreditación o reacreditación, sino también en lo referente a la extensión social e investigación que realizan. Sin embargo, en las diferentes universidades parece evidente que más allá de estos mecanismos divulgativos, no se han utilizado otros formatos que visibilicen el aseguramiento de la calidad ni otras dimensiones que se le asocian.

Existe también la posición de que la agencia SINAES debe divulgar y promover más las funciones y responsabilidades que tiene, y contribuir a que el público comprenda en realidad lo que implica una acreditación, así como lo que no significa;

por ejemplo, algunas autoridades insisten en que acreditarse no significa que se pueda comparar una misma carrera acreditada en dos universidades diferentes, ya que aunque esas carreras cumplen con los criterios de calidad que el SINAES ha establecido, se han evaluado contra su propio proyecto educativo.

Solo una tercera parte del grupo de estudiantes activos consultados (33\%) tiene conocimiento de algún sistema que informe al público en general sobre los resultados de los procesos de acreditación o certificaciones de calidad de las universidades.

Finalmente, es importante anotar que la información que los y las estudiantes recibieron sobre los procesos de acreditación influyó en la decisión, en cuatro de cada diez, sobre el centro educativo dónde estudiar, así como en el programa seleccionado, en cuatro de cada diez personas. Los y las estudiantes de universidades privadas se vieron mayormente influenciados por esta información, que aquellos de universidades estatales, tanto en la decisión del centro educativo como en el programa o carrera que estudian actualmente.

\section{Internacionalización del trabajo de aseguramiento de la calidad}

El proyecto definió que en esta dimensión de calidad se indagaría acerca del efecto internacionalizante que pueden tener sobre la oferta educativa, el desarrollo de procesos de aseguramiento de la calidad (Proyecto Alfa Nro. DCl-ALA 2008/42, s.f., p. 3).

Las personas consultadas en las universidades participantes manifiestan que trabajan en el desarrollo de mecanismos, criterios y procedimientos que favorezcan las equivalencias, ya que, en general, consideran que una persona egresada de la universidad debe poder acceder, de manera fluida, a las ventajas de una oferta educativa internacionalizada. 
A grandes rasgos, se considera que la estandarización y homologación de programas y títulos son acciones complejas en la región centroamericana dado el sistema de grados y postgrados y la nomenclatura de las titulaciones, que son diferentes a los de otros países de fuera de esta región. Es por ello que se considera más factible el reconocimiento de profesiones que de títulos. A pesar de esto, parece existir un consenso en el sentido de que la movilidad estudiantil y profesional se facilita cuando las carreras están acreditadas.

En este tema de internacionalización algunas universidades han buscado favorecer la acreditación con agencias internacionales, sobre todo, con la Canadian Engineering Accreditation Board (CEAB); se ha fomentado el involucramiento en procesos de aseguramiento de la calidad, ya que, en general, se considera que los procesos de acreditación y certificación son garantes de estos mecanismos de internacionalización. Asimismo, algunas universidades han fortalecido la formación estudiantil mediante un currículo basado en competencias porque lo consideran más acorde con las tendencias actuales de formación profesional que favorece el reconocimiento y la movilidad estudiantil.

\section{Nivel II: Gestión institucional}

\section{Instalación de mecanismos y procesos de aseguramiento de la calidad}

En esta dimensión se indagó acerca de la creación de instancias, políticas y/o mecanismos que se han instaurado en las universidades para asegurar la calidad de sus programas (Proyecto Alfa Nro. DCl-ALA 2008/42, s.f., p. 6).

Dentro de los hallazgos encontrados se tiene que las personas consultadas en las universidades coinciden al señalar una serie de mecanismos que se han puesto en práctica con el fin de asegurar la calidad de sus programas y responder a los requerimientos de aseguramiento de la calidad. Dentro de los mecanismos mencionados se encuentra la creación, o el mejoramiento, de los programas de educación continua y de los programas de formación y evaluación docente, así como la creación de cursos para directivos universitarios, sobre todo, enfocados a los temas de la gestión y el liderazgo universitarios.

Una universidad señaló la instalación de un sistema con parámetros de calidad que se aplica a todo cambio, sea de naturaleza curricular o de infraestructura, que se realice en la universidad; además, se mencionan los intentos por tener una visualización integral del currículum, donde se tome en consideración el desarrollo académico docente, el desarrollo y 
desempeño estudiantil, la infraestructura, el equipamiento y la pertinencia, todo esto dentro de un modelo de gestión acorde con el aseguramiento de la calidad.

También, las universidades consultadas mencionan el establecimiento de mecanismos permanentes de autoevaluación y una cultura permanente de autorevisión de sus carreras, así como una intención explícita de establecer procesos de interacción (negociación) entre las carreras y las Oficinas de Planificación de las universidades.

En las universidades privadas consultadas, se han desarrollado modelos propios con el fin de darle seguimiento al cumplimiento de los indicadores de calidad. Esta nueva perspectiva ha implicado la promoción y capacitación docente, una actitud hacia el estímulo del desarrollo académico desde una perspectiva académica vinculada con la investigación. También, han puesto en marcha mecanismos permanentes de autoevaluación como forma de revisar constantemente los procesos internos de las unidades y las necesidades de mejora en función de una gestión hacia la calidad, tales mecanismos también se ajustan a la misión y visión de las estas universidades, y a sus planes estratégicos.

\section{Desarrollo de sistemas de información}

En esta dimensión se recopilaron las percepciones de las diferentes poblaciones consultadas, acerca de la generación de información o de datos institucionales sobre las distintas funciones que se realizan en las universidades (Proyecto Alfa Nro. DCl-ALA 2008/42, s.f., p. 6).

Los hallazgos encontrados evidencian que, como parte de la aplicación de mecanismos de aseguramiento de la calidad, en las universidades consultadas se han desarrollado diversos sistemas de manejo de la información interna, para la toma de decisiones. En cada una de las universidades del estudio existe un sistema para el manejo de la información interna; en algunas de ellas, se destacan tales sistemas como procesos más avanzados en su desarrollo, en otras se indica que más bien se encuentran en procesos iniciales. En todos los casos, se afirma la importancia y necesidad de estos sistemas ordenados para favorecer la toma de decisiones en la gestión administrativa institucional actual.

En las universidades públicas, el desarrollo de estos sistemas parece estar más encausado y avanzado hacia la disponibilidad interna de la información, el seguimiento y la 
gestión de los procesos académicos. En las universidades privadas se percibe, además, un mayor desarrollo hacia el monitoreo y análisis de los procesos financiero-administrativos.

En general, las autoridades consultadas coinciden en que se ha invertido en sistemas de información para generar indicadores para la gestión de calidad en temas relacionados con la gestión académica, las tasas de aprobación, reprobación y deserción y para monitorear evaluaciones docentes.

Los sistemas de información que apoyan los procesos de evaluación de las carreras se utilizan, particularmente, para darle seguimiento a procesos internos tales como: admisiones y matrícula, tasas de ingreso, aprobación, reprobación y deserción, procesos de comunicación digitales entre alumnos y docentes, para generar información sobre presupuestos operativos, de inversión y de gastos, para perfilar metas administrativas y para favorecer los mecanismos de matrícula en línea o de "expediente único" del personal docente y administrativo.

En general, se encontró que en las universidades de carácter estatal, los sistemas de información existen, pero se encuentran en procesos de mejora. En estas universidades, las personas entrevistadas manifiestan una deficiencia en el manejo de datos administrativos del personal administrativo y académico, ya que no cuentan con información única, coherente y precisa y no se comparte toda la información de forma transparente. En las universidades de carácter privado, se invierte de manera constante en la compra de sistemas operativos para apoyo a la toma de decisiones.

Casi la totalidad de los y las estudiantes (98\%) tienen conocimiento de la existencia, en su universidad, de algún sistema de información que les permita estar al tanto de su situación académica en temas como cursos matriculados, materias aprobadas y reprobadas así como el record de sus calificaciones, entre otros.

\section{Gestión, gobierno y administración de las instituciones de Educación Superior y sus programas}

En esta dimensión se les consultó a los diferentes participantes acerca de los cambios que pudieran manifestarse en los procesos de gestión institucional (Proyecto Alfa Nro. DClALA 2008/42, s.f., p. 7). Las personas consultadas en las cuatro universidades coinciden al afirmar que los mecanismos de aseguramiento de la calidad, concretamente los procesos de 
acreditación de las carreras, han ayudado a aclarar y articular proyectos institucionales y a mejorar algunos aspectos de los procesos de la gestión institucional.

Con los compromisos de mejora que presentan las carreras que se acreditan, se articulan los procesos de planificación universitaria con los de aseguramiento de la calidad. En este proceso de gestión institucional, se nota la participación de la agencia de acreditación nacional, que monitorea y verifica el cumplimiento de los procesos de mejora contenidos en los compromisos de mejoramiento de las carreras.

Otro aspecto señalado por las universidades se refiere al mecanismo por medio del cual las carreras acreditadas ingresan dentro de un sistema de formulación de presupuesto universitario, que les asigna prioridad con respecto a otras carreras no acreditadas.

\section{Gestión académica institucional}

En esta dimensión se les consultó a los diferentes actores acerca de los cambios que pudieran manifestarse en los procesos de gestión académica institucional (Proyecto Alfa Nro. DCl-ALA 2008/42, s.f., p. 7). La aplicación de mecanismos de aseguramiento de la calidad ha implicado, para las cuatro universidades consultadas, la revisión de la oferta académica, y un "ponerse al día" en cuanto a la pertinencia de sus planes de estudio. Concretamente, las instituciones han experimentado revisiones curriculares, replanteamientos de las tecnologías utilizadas, reposicionamiento del área de idiomas dentro de la estructura curricular, mayor monitoreo del entorno y de las necesidades del país, constante valoración de las necesidades de empleadores y revisión de los perfiles de egreso de las carreras.

Algunas universidades reportan un mayor contacto con las demandas y necesidades del sector empleador y del mercado laboral, lo cual ha implicado, en algunas ocasiones, la creación de carreras nuevas que responden a demandas emergentes del entorno nacional e internacional.

Asimismo, en las universidades se observan acciones desarrolladas en las instancias encargadas de la gestión académica, tendientes a mejorar la formación de docentes y al aseguramiento de la calidad e idoneidad del personal académico. También, en algunas universidades se han desarrollado mecanismos para el monitoreo de planes y programas, sistemas permanentes de evaluación (tanto docente como curricular) y mayores regulaciones en el control de los planes de estudio de las carreras, como una forma de responder a los requerimientos de los cambios tecnológicos. 
En general, las universidades han mejorado los recursos destinados a la docencia, dentro de los que se encuentran: la mayor dotación de recursos tecnológicos, la incorporación de la red de internet en las aulas universitarias, la remodelación de laboratorios, la instalación de bibliotecas virtuales y la compra de softwares específicos.

La percepción de las mejoras en el plan de estudios de la carrera es un aspecto en el que se muestra diferencia entre estudiantes de universidades estatales y privadas. Estos últimos perciben un impacto más positivo, $20 \%$ de las personas consultadas, contra un $13 \%$ proveniente de las universidades estatales. Además, los cambios o mejoras en la participación de los estudiantes en la evaluación de los planes de estudio de sus carreras son calificados muy positivamente (han mejorado mucho) por el 15\% de las personas consultadas; el 55\% manifestó que dichas variantes "han tenido alguna mejora" y el 19\% se mostró insatisfecho con dicho aspecto.

La incorporación del uso de tecnologías y otras innovaciones en la docencia son reconocidos por los y las estudiantes, como los elementos con mayor evolución. El 51\% considera que dicho recurso ha mejorado "mucho" y $43 \%$ opina que ha mejorado en "algo".

\section{Gestión administrativa y financiera}

En esta dimensión se indagó acerca de los cambios ocurridos en el ordenamiento institucional y en las funciones de gestión de las instituciones de Educación Superior, tanto a nivel administrativo como financiero (Proyecto Alfa Nro. DCl-ALA 2008/42, s.f., p. 8).

Las percepciones obtenidas evidencian que la aplicación de diversos mecanismos de aseguramiento de la calidad, y sobre todo los procesos de acreditación de las carreras, han generado algunos cambios en los procesos administrativos de las universidades, los que se visualizan, por ejemplo, en cambios en el manejo presupuestario de algunas universidades, donde se ha pasado de tener un manejo centralizado a ceder a las escuelas la administración de parte del mismo; esto ha originado variaciones en la configuración de los actores que manejan presupuesto en las instituciones de Educación Superior consultadas.

También, las universidades señalan más claridad y transparencia en el uso de los recursos y en esto se reconoce la importancia de la implementación de los sistemas de información existentes, que han facilitado la eficiencia en los procesos internos de algunas universidades. 
No obstante, han habido cambios importantes en la dotación de recursos a las entidades y carreras que, dentro de sus procesos de evaluación, justifican la necesidad; por ejemplo: equipos nuevos y recurso humano docente, esto ha implicado, sin embargo, una especie de lucha entre unidades académicas, porque hay políticas de priorización entre unas y otras.

En cuanto a la opinión del sector estudiantil que se consultó en este estudio, el de las universidades estatales percibe con mayor intensidad los beneficios y las mejoras en la eficiencia de los "procesos de matrícula" y "proceso de inscripción de asignaturas". Comparativamente con los estudiantes de universidades privadas, se identificaron diferencias estadísticamente significativas, al 5\%, entre ambos segmentos: el $45 \%$ de las personas consultadas de universidades estatales consideran que el proceso de matrícula "ha mejorado mucho" versus el $26 \%$ de los estudiantes de centros educativos privados. Complementariamente, el $23 \%$, de estos últimos, mencionaron que los procesos de inscripción de materias "ha mejorado mucho" frente al 33\% de los estudiantes de centros educativos estatales.

\section{Participación de grupos de interés en procesos de aseguramiento de la calidad. Generación de una cultura de calidad}

Esta dimensión del estudio estaba orientada a ahondar en los niveles de compromiso y de participación de los actores internos (docentes, estudiantes, personal de apoyo) y externos al sistema universitario (como sectores profesionales y empleadores) (Proyecto Alfa Nro. DCl-ALA 2008/42, s.f., pp. 8-9). La aplicación de diversos mecanismos de aseguramiento de la calidad en las universidades consultadas permite visualizar un cambio en la relación, contacto e involucramiento, que se establece con los actores internos y externos vinculados con el proceso educativo.

Los hallazgos encontrados en este sentido señalan que, con respecto a los actores internos, se ha buscado incrementar el contacto permanente con estudiantes para reflexionar sobre temas de la carrera y, en general, se valora como positiva la influencia de este sector en la toma de decisiones de las carreras. En relación con esto, aproximadamente seis de cada diez estudiantes consultados ha participado o conoce de algún compañero(a) que haya participado en encuestas, reuniones o grupos focales para evaluar el funcionamiento de la carrera o programa que cursan. Estos resultados no muestran diferencias significativas, al 
$5 \%$, entre los estudiantes de universidades públicas y privadas. Asimismo, un $12 \%$ del grupo estudiantil consultado considera que la influencia de la participación de los estudiantes en la toma de decisiones al interior de las carreras "ha mejorado mucho", mientras que seis de cada diez entrevistados consideran que las mejoras han sido también positivas, pero con menor intensidad o magnitud ("ha tenido alguna mejora").

En cuanto a los actores externos al sistema universitario, las autoridades universitarias consultadas señalan el mayor contacto establecido con personas egresadas y empleadoras y el incentivo a desarrollar, en las empresas, las prácticas profesionales de las carreras. Específicamente, dos de cada tres de las personas egresadas consultadas para este estudio manifestaron que se les han solicitado participar o han conocido a algún compañero (a) que le han solicitado participar, en encuestas, reuniones o grupos focales para evaluar la carrera o la universidad donde estudiaron.

Otro aspecto al que se refirieron las personas entrevistadas, es al desarrollo de investigaciones relacionadas con las necesidades de las empresas y a una mayor vinculación con los colegios o gremios profesionales, para aspectos puntuales como desarrollo de grupos focales, o para emitir opinión sobre reconocimientos de títulos, por ejemplo. Se señala una mayor relación con el sector empresarial mediante el desarrollo de diversas estrategias para mantener la vinculación con este grupo, por ejemplo, por medio de programas de actualización, consultorías, ofertando capacitaciones a las empresas, o mediante el servicio de seminarios, talleres y conferencias.

En concordancia con lo anterior, la mayoría de los cinco colegios o gremios profesionales consultados en este estudio, manifestó que han sido invitados directamente por las universidades para tener algún tipo de participación y realimentar los procesos de autoevaluación de las carreras, por medio de reuniones y grupos focales.

\section{Redefinición de las funciones universitarias (cambios en el peso relativo)}

En esta última dimensión se exploró acerca del efecto que los procesos de autoevaluación y evaluación externa tienen sobre la definición de las funciones universitarias, la valorización de las características de la docencia y sus resultados (Proyecto Alfa Nro. DCl-ALA 2008/42, s.f., p. 9).

Entre los hallazgos encontrados en este estudio, se tiene que en todos los casos, las universidades destacan la importancia de contar con docentes titulados, que cuenten como 
mínimo con un título de postgrado. Paralelo a esto, se destaca también la necesidad de formaciones sólidas sobre estrategias didácticas pertinentes, según los requerimientos de las disciplinas o las carreras. Consecuentemente, la mayoría de las universidades ha puesto en marcha programas de formación para los y las docentes, tanto en el campo disciplinar propiamente, como en el área pedagógica.

No se señalan cambios específicos y particulares en ninguna universidad en los sistemas de contratación del personal docente, pero sí se hacen señalamientos en cuanto a la creación de sistemas de remuneración y de estímulos a los docentes.

El sector estudiantil consultado considera que han percibido cambios en la forma en que se evalúa al cuerpo de profesores. Por ejemplo, el $18 \%$ de los estudiantes de universidades públicas consideran que los mecanismos de evaluación "han mejorado mucho", frente a un $13 \%$ del estudiantado de las universidades privadas. En ambos sectores (público y privado) cerca del $50 \%$ considera que dichos procedimientos "han tenido alguna mejora".

\section{Nivel III: Gestión de la docencia}

\section{Revisión de perfiles de egreso, planes de estudio, currículo}

Esta dimensión se enfocó en conocer el grado en que los procesos de aseguramiento de la calidad promueven la revisión de los perfiles de egreso de la oferta educativa y los cambios curriculares (Proyecto Alfa Nro. DCl-ALA 2008/42, s.f., p. 9). De acuerdo con lo anterior, es importante mencionar que la revisión de los perfiles de egreso de los planes de estudio y, en general de la propuesta curricular de las carreras acreditadas, es uno de los impactos más claros que señalan las universidades consultadas.

En términos generales, la evolución de los diseños y las innovaciones curriculares se han dirigido a lograr una mayor articulación entre el grado y la formación de postgrado, a promover la formación de centros de Investigación específicos, a fomentar el uso de la tecnología, a garantizar el dominio de un segundo idioma y a la incorporación de las denominadas "competencias blandas" en el currículum, tales como el liderazgo, el desarrollo de la imagen, la comunicación interpersonal y asertiva así como el trabajo en equipo.

En estos procesos de actualización curricular, los actores externos han desempeñado un papel importante, de acuerdo con lo manifestado por las personas entrevistadas de cada universidad, ya que los sectores empleadores y los colegios o gremios profesionales, por 
ejemplo, participan en la validación de perfiles de egreso y en las consultas sobre las condiciones actuales del mercado profesional y laboral.

A nivel institucional, las universidades reportan un mayor fomento al trabajo comunal universitario y, en general, sus actividades de extensión o proyección social; también, las carreras manifiestan un incremento en la frecuencia con que se realizan las reuniones con los sectores de empleadores y con la población egresada.

La incorporación en el currículum de cursos que aborden habilidades generales, como comprensión de lectura, expresión oral y escrita y matemáticas, entre otros, ha sido percibida muy positivamente tanto por estudiantes de universidades estatales como privadas (15\% y 19\% respectivamente consideran que "ha mejorado mucho").

Finalmente, es importante mencionar que la vinculación entre la formación recibida en la universidad y la oferta laboral es valorada muy positivamente por seis de cada diez egresados (as) de carreras acreditadas, que fueron entrevistados para este estudio. Sin embargo, este resultado difiere significativamente entre estudiantes de universidades estatales y privadas: $71 \%$ de las personas consultadas egresadas de universidades estatales consideran que su formación se vincula "mucho" con los requerimientos del mundo laboral, mientras que un $56 \%$ de las personas egresadas de las universidades privadas opinan esto.

\section{Análisis de información sobre progresión y logros}

Esta dimensión se refiere a la consideración sistemática de información relativa a las características del estudiantado matriculado, a su seguimiento y los logros obtenidos (Proyecto Alfa Nro. DCl-ALA 2008/42, s.f., p. 10). Es así como las universidades consultadas coinciden al afirmar que con los compromisos de mejora asumidos en los procesos de acreditación, sobre todo, han desarrollado algún tipo de sistema de información para dar seguimiento sistemático a estudiantes; a pesar de que el grado de avance y de utilización de estos sistemas varía de universidad en universidad, todas presentan un gran interés en este aspecto.

Dentro de esto, tiene un especial énfasis el desarrollo de sistemas de información para el seguimiento sistemático de los índices de rendimiento académico y para detectar, y darle seguimiento, a las necesidades especiales que pueda presentar esta población, pero en la mayoría de los casos aún no se cuenta con estos sistemas desarrollados en su totalidad. Es así como el registro de las características del estudiantado, así como el seguimiento de su 
desempeño tiene, entonces, diferentes desarrollos en las universidades consultadas, ya que en algunas de ellas por ejemplo, las tasas de repitencia y el incremento en los años para graduarse, constituyen problemáticas que se repiten año a año.

\section{Evaluación de resultados de los aprendizajes}

Esta dimensión de calidad busca indagar acerca de las iniciativas para evaluar los resultados efectivos de aprendizaje que tiene el estudiantado en las instituciones de Educación Superior (Proyecto Alfa Nro. DCl-ALA 2008/42, s.f., p. 10). Las percepciones de la mayoría de los actores consultados, tienden a considerar que el modelo de acreditación del SINAES no les permite a las carreras, ni a las universidades obtener información sobre el aprendizaje real que tienen los y las estudiantes, por lo que las universidades han implementado acciones concretas que les permitan valorar la efectividad de los aprendizajes. Es así como algunas de las universidades consultadas mencionan que han desarrollado planes para capacitar a los y las docentes y han hecho intentos por enfocarse en una evaluación más basada en aprendizajes y no tanto en contenidos.

En su mayoría, las personas entrevistadas mencionan que las universidades han desarrollado mecanismos que les permiten monitorear mejor los aprendizajes alcanzados y que cuentan con más reglamentación, normas y controles al respecto.

Las variantes en metodologías o formas de enseñanza son calificadas de igual forma por los estudiantes de universidades públicas y privadas: el 17\% considera que los cambios han propiciado un mejoramiento significativo ("ha mejorado mucho") y un 69\% considera que los beneficios han sido positivos, pero "más leves".

\section{Formación pedagógica de los y las docentes}

En esta dimensión de calidad definida en el proyecto se indaga acerca de los procesos que se desarrollan en las universidades, tendientes a mejorar la formación en pedagogía y didáctica de los docentes (Proyecto Alfa Nro. DCl-ALA 2008/42, s.f., p. 9). De las entrevistas y grupos focales realizados se puede extraer la información de que en todas las universidades consultadas, el tema de la capacitación y formación pedagógica del personal docente ha tomado una importancia estratégica y fundamental para mejorar el éxito y el rendimiento académico del estudiantado. 
Es así como las universidades han desarrollado procesos de capacitación y programas especiales tendientes a mejorar las capacidades docentes del cuerpo profesoral. Estos programas incluyen los temas de pedagogía, didáctica, utilización de las tecnologías informáticas en los procesos de enseñanza y aprendizaje, entre otros.

Además, algunas universidades realizan esfuerzos tendientes a potenciar la aplicación de metodologías innovadoras en función de las características de la población estudiantil, desarrollan iniciativas para la implementación de las tecnologías de la información y la comunicación y buscan una mayor vinculación con las empresas como manera de enriquecer sus procesos de enseñanza.

En este aspecto, el 15\% del sector estudiantil consultado percibe mejoras con "alta intensidad" en la forma en que los y las docentes imparten las clases; sin embargo, a esta valoración positiva se une el $73 \%$ que percibió modificaciones beneficiosas pero con menor fuerza ("ha tenido alguna mejora").

\section{Estrategias pedagógicas}

En esta dimensión se busca recoger información acerca de la forma en que se desarrolla la práctica docente (Proyecto Alfa Nro. DCl-ALA 2008/42, s.f., p. 9). Las personas consultadas en las universidades participantes en este estudio manifiestan que se han desarrollado diversos mecanismos para que los y las docentes compartan sus experiencias en la aplicación de ciertas técnicas, dinámicas o las metodologías particulares que utilizan en el aula. También, se evidencia un creciente interés por fomentar la innovación tecnológica dentro de la función pedagógica del cuerpo docente.

El profesorado entrevistado manifestó, en general, su interés por incorporar innovaciones pedagógicas en sus funciones docentes; sin embargo, es notorio el rezago de algunas carreras con respecto a otras; también, se destaca que en los planes de mejora de las carreras acreditadas normalmente se solicitan recursos para tales efectos, como por ejemplo, para colocar acceso a la internet en todas las aulas o comprar equipo audiovisual.

Se reconoce que la incorporación de nuevas tecnologías a la práctica docente se ha originado en muchos casos por iniciativa e interés del docente o por la misma presión por parte del alumnado, pero que la maximización de su uso depende en gran parte del profesor o profesora, ya que las facilidades que otorga la universidad, en este sentido, no son de uso obligatorio por parte del personal académico. 
En este aspecto, el sector estudiantil consultado, sin mostrar diferencias significativas, al 5\%, por tipo de universidad, valora de manera muy positiva los recursos relacionados con la universidad, la carrera y el programa tales como la disponibilidad de recursos didácticos (computadoras, libros), infraestructura de las salas de clases, espacios de estudio y bibliotecas, y los servicios complementarios como la soda o los servicios de fotocopiado.

\section{Cambios en la evaluación del personal académico}

En esta dimensión de calidad definida en el proyecto se busca conocer los cambios en los criterios y procedimientos de evaluación del personal académico (Proyecto Alfa Nro. DClALA 2008/42, s.f., p. 11). En todas las universidades consultadas se implementan sistemas para la evaluación docente, los que se han desarrollado de manera independiente de los procesos de autoevaluación y acreditación, y forman parte de los mecanismos de aseguramiento de la calidad de las universidades. En todas las instituciones se realizan esfuerzos para fortalecer no solo los sistemas de evaluación docente, sino también por mejorar la formación y actualización de este personal.

En una universidad consultada sí se reporta la incorporación de los criterios de la agencia SINAES a su sistema de evaluación de la idoneidad docente, el cual se sustenta en criterios definidos por la propia universidad.

\section{Responsabilidad institucional por los resultados del proceso de enseñanza y aprendizaje}

Con esta última dimensión del nivel de docencia, el proyecto busca recoger información acerca del diseño, implementación y evaluación de programas remediales o compensatorios, o estrategias de acompañamiento para estudiantes de primer ingreso, con el fin de mejorar los indicadores de progresión y éxito pedagógico (Proyecto Alfa Nro. DClALA 2008/42, s.f., p. 11). En este sentido, debe mencionarse que el seguimiento a estudiantes con condiciones particulares en su desempeño académico es una política que ha existido de forma regular, y durante más de 20 años, en una institución consultada. En este caso, se reconoce que por medio de los procesos de acreditación ha habido más comunicación con las instancias universitarias que acompañan a los y las estudiantes durante su formación universitaria, para la realización de planes remediales, seguimientos y planes de acción individual con un enfoque integral de la situación particular. 
En las otras universidades consultadas, la atención a este tema es más reciente, pero han desarrollado una diversidad de maneras para acompañar a los y las estudiantes de primer ingreso tales como: diversos programas de apoyo, aplicación de adecuaciones curriculares significativas y no significativas, mediante estudiantes monitores o asesores (estudiantes que han logrado aprobar los cursos de forma exitosa y tienen una cierta vocación para ayudar a otros) o mediante la asignación de profesores-asesores a los que se les paga un monto adicional por dar asesorías/tutorías. Otra universidad menciona los procedimientos que han tenido siempre, pero que se evidenciaron y potencializaron por la incursión en procesos de aseguramiento de la calidad, tales como el desarrollo de procesos de evaluación cualitativa a mitad del curso, donde se hace una evaluación de la evolución y desempeño que va teniendo cada estudiante, lo que permite darle seguimiento a los casos específicos.

En general, con la ejecución de los procesos de acreditación, las autoridades de las universidades señalan que se utilizan más los servicios de otras oficinas universitarias que apoyan al sector estudiantil. En este aspecto existe coincidencia con lo expresado por los y las estudiantes consultados en este estudio, ya que una cuarta parte de este sector ha percibido mejoras significativas ("ha mejorado mucho") en el apoyo a las personas que experimentan dificultades académicas mediante la apertura de espacios como reforzamientos o tutorías; el 50\% percibió que esos cambios han tenido efectos satisfactorios pero con menor intensidad ("ha tenido alguna mejora").

Las mejorías en la calidad de los servicios de bienestar como atención médica, dental y psicológica, entre otras, son valoradas más positivamente por los estudiantes de universidades estatales (36\%, mientras que para las privadas constituye un 19\%).

\section{Conclusiones generales}

Este estudio es pionero en la región, debido a que existe muy poca información acerca de los impactos, que la implementación de los diversos mecanismos de aseguramiento de la calidad están teniendo en las instituciones de Educación Superior, a pesar de que en nuestro país tales mecanismos se implementan, de manera sostenida, desde mediados de los años noventa. Sin embargo, existe cierto consenso de que estos mecanismos sí están teniendo algún impacto en diversas esferas del accionar institucional y docente, pero que son difíciles de medir (Proyecto Alfa Nro. DCl-ALA 2008/42, 2011, junio). 
Debe destacarse en este apartado que, tal y como se mencionó en el marco referencial, en este estudio no se pretendía establecer correspondencias directas entre la implementación de algunos mecanismos de aseguramiento de la calidad en las instituciones de Educación Superior, y las medidas adoptadas por las universidades en los ámbitos institucionales, de gestión administrativa y de gestión y desarrollo académico. En este aspecto fueron muy enfáticas la gran mayoría de las personas consultadas para este estudio en Costa Rica y, dada la configuración del sistema de Educación Superior costarricense, las universidades muestran estadios muy diferentes en el desarrollo e implementación de estos mecanismos por lo que, para analizar y comprender sus impactos, también debe considerarse la interacción de una serie de factores propios de la historia, cultura y evolución de cada institución de Educación Superior.

En el marco referencial del proyecto se hizo alusión a esta dificultad de establecer relaciones de causalidad entre la aplicación de determinados mecanismos de aseguramiento de la calidad y los cambios que se pudieran observar, percibir o detectar en las universidades participantes, a esto debe agregarse también, que, debido a la metodología utilizada, predominantemente cualitativa, este estudio se enmarca, más bien, dentro de un estudio que intenta conocer las percepciones de actores seleccionados, de universidades seleccionadas (Proyecto Alfa Nro. DCl-ALA 2008/42, 2011, setiembre).

Se considera que, a pesar de que uno de los objetivos del proyecto se formuló como una evaluación de impacto, los hallazgos encontrados, al constituir percepciones de un conjunto de sectores y actores vinculados con el sistema de Educación Superior en Costa Rica, no permiten determinar, de manera categórica, si la incorporación de estos mecanismos de aseguramiento de la calidad produjeron los efectos deseados en las diferentes instancias estudiadas, ya que no es posible, con la información recabada, evaluar, o establecer una correspondencia directa, o relación de causalidad, entre los diversos efectos o resultados manifestados en las universidades y la incorporación de estos mecanismos.

A pesar de las consideraciones anteriores, los resultados obtenidos evidencian que la instalación e implementación de procesos y mecanismos de aseguramiento de la calidad han favorecido, intensificado o propiciado ciertos cambios en las instituciones y en las carreras universitarias, los cuales, sin ser todas, se enlistan seguidamente: 


\section{Nivel I: Sistema de Educación Superior}

a. En las universidades consultadas, se visualiza una tendencia a establecer cierta equivalencia entre los mecanismos de aseguramiento de la calidad y la acreditación de programas y carreras universitarios. En general, existe la creencia de que acreditarse conlleva necesariamente mejoras por varios motivos, dentro de los que más mencionados se encuentran que permite el "acceso fácil" a recursos financieros, al incremento de plazas académicas en las carreras, a la actualización curricular y al mejoramiento de las capacidades de los talentos humanos.

b. En todas las universidades participantes se han desarrollado instancias propias encargadas del resguardo de la calidad, algunas cuentan con mayor antigüedad y experiencia que otras; además de este apoyo que las universidades le brindan a las carreras que se autoevalúan, en estos procesos, el personal docente universitario se involucra en las autoevaluaciones y acreditaciones y asume papeles académicos, logísticos y operativos.

c. En general, persiste una opinión favorable hacia la acreditación, pero se considera que el modelo que es utilizado por la agencia acreditadora es muy generalista y no permite valorar especificidades de las carreras. Es evidente el reconocimiento de la importancia y de los beneficios asociados a los procesos de aseguramiento de la calidad; no obstante, surgen algunas críticas respecto a la implementación de estos mecanismos, especialmente en lo relacionado con los criterios de evaluación y acreditación (Proyecto Alfa Nro. DCl-ALA 2008/42, 2011, junio).

d. Es evidente la mayor conciencia acerca de la importancia del mejoramiento de la confiabilidad y la transparencia de la información; sin embargo, todavía se presentan problemas de sistematización y acceso (Proyecto Alfa Nro. DCl-ALA 2008/42, 2011, junio). En este sentido se destaca la falta de información clara y precisa sobre los resultados de la aplicación de los diversos mecanismos de aseguramiento de la calidad en las instituciones de Educación Superior, dirigida hacia el público en general. En las universidades existe coincidencia respecto a este punto y detectan las deficiencias tanto en la transmisión de la información como en la efectividad de los mecanismos que la visibilicen. Al respecto, en Costa Rica se presenta una diferencia entre universidades públicas y privadas. 
e. Se considera que ha habido poco avance de los procesos de internacionalización y su relación con el aseguramiento de la calidad (Proyecto Alfa Nro. DCl-ALA 2008/42, 2011, junio).

\section{Nivel II: Gestión institucional}

f. En las universidades se ha acelerado la gestión de cambios institucionales a partir de las debilidades encontradas por las carreras en sus procesos de autoevaluación, esto ha permitido desarrollar diversos programas permanentes de formación y evaluación docente así como sistemas de información y operativos.

g. Todas las universidades consultadas coinciden al señalar una serie de mecanismos que se han puesto en práctica con el fin de asegurar la calidad de sus programas y responder a los requerimientos de aseguramiento de la calidad, así como para cumplir sus objetivos y las metas institucionales.

h. Los sistemas de información están en desarrollo y su grado de sistematización, así como de utilización para la toma de decisiones, varía mucho en cada universidad.

i. Con los compromisos de mejora que presentan las carreras que se acreditan, se considera que se articulan los procesos de planificación universitaria con los de aseguramiento de la calidad.

j. La aplicación de mecanismos de aseguramiento de la calidad ha implicado, para las cuatro universidades consultadas, la revisión de la oferta académica, y actualización en cuanto a la pertinencia de sus planes de estudio y la vinculación con el mundo laboral.

k. Se evidencian cambios importantes en la dotación de recursos a las entidades y carreras, ya que se han redefinido los criterios para asignar recursos económicos, de acuerdo con las necesidades estipuladas en los planes de mejoramiento de las carreras que se acreditan.

I. Las carreras acreditadas muestran tener un creciente contacto con los actores internos y externos, para la implementación de diversos procesos de aseguramiento de la calidad.

m. El papel del profesorado universitario adquiere mayor relevancia en el diseño e implementación de diversos mecanismos de aseguramiento de la calidad y todas las universidades consultadas evidencian haber desarrollado planes concretos para el perfeccionamiento y actualización pedagógica de esta población. 


\section{Nivel III: Docencia}

n. La revisión de los perfiles de egreso de los planes de estudio, y en general de la propuesta curricular de las carreras acreditadas, es uno de los impactos más claros que señalan las universidades consultadas. En esto desempeñan un papel cada vez más visible, los agentes externos de las universidades, tales como empleadores y sectores profesionales.

o. Se considera que tienen un desarrollo desigual los sistemas de información desarrollados en las universidades, para dar seguimiento sistemático a la información relativa a los y las estudiantes.

p. Las percepciones de la mayoría de los actores consultados consideran que el modelo de acreditación del SINAES no les permite a las carreras, ni a las universidades, obtener información sobre el aprendizaje real que tienen los y las estudiantes, por lo que las universidades han implementado acciones concretas que les permitan valorar la efectividad de los aprendizajes alcanzados; además, señalan que al respecto, cuentan con más reglamentación, normas y controles

q. Se muestra un creciente y decido interés por mejorar la formación pedagógica del cuerpo profesoral y el desarrollo de programas de capacitación y formación docente.

En cuanto a los actores sociales involucrados en este estudio, debe señalarse que, en general, los gremios o colegios profesionales desconocen los resultados de los procesos de aseguramiento de la calidad de las universidades, aunque manifiestan tener credibilidad en la agencia de acreditación, a pesar de que no tienen claro cuáles son los criterios y métodos para la acreditación de las carreras.

Finalmente, es importante mencionar algunos aspectos generales que se encontraron, de manera común, en todos los estudios realizados en los siete países.

De manera general, se considera que hay más impacto cuando:

- Los mecanismos de aseguramiento de la calidad reconocen y validan la autonomía institucional y se reconoce que la responsabilidad de la calidad es de las universidades.

- Existen recursos e incentivos asociados para la implementación de los planes de mejoramiento.

- Están vinculados a otros instrumentos de políticas. 
- Existe un compromiso real de las autoridades a nivel central.

- Los mecanismos de aseguramiento de la calidad forman parte de un sistema mayor de gestión de la calidad (Proyecto Alfa Nro. DCl-ALA 2008/42, 2011, junio).

Los resultados de este estudio brindan insumos importantes para comprender el estado actual de la calidad en las instituciones de Educación Superior, lo que permite tomar las medidas del caso a las instancias respectivas: agencia de acreditación, autoridades universitarias, carreras, personal académico, e instancias formuladoras de políticas que implican de manera directa a la Educación Superior.

\section{Referencias}

Centro Interuniversitario de Desarrollo. (2006). Antecedentes y programas. Chile: CINDA.

Centro Interuniversitario de Desarrollo. (2008). Planteamiento del proyecto Aseguramiento de la Calidad: políticas públicas y gestión universitaria. Chile: CINDA.

Programa Estado de la Nación. (2011). Tercer Informe Estado de la Educación (Capítulo 1: Sinopsis). San José, Costa Rica: El Programa.

Proyecto Alfa Nro. DCl-ALA 2008/42. Aseguramiento de la Calidad: políticas públicas y gestión universitaria. (2009a). Informe Nacional-Costa Rica. Costa Rica: El autor.

Proyecto Alfa Nro. DCl-ALA 2008/42. Aseguramiento de la Calidad: políticas públicas y gestión universitaria. (2009b). Marco de referencia para el proyecto sobre aseguramiento de la calidad. Chile: El autor.

Proyecto Alfa Nro. DCl-ALA 2008/42. Aseguramiento de la Calidad: políticas públicas y gestión universitaria. (2011a). Informe de Evaluación de impacto de los mecanismos de aseguramiento de la calidad en la Educación Superior-Costa Rica. Costa Rica: El autor.

Proyecto Alfa Nro. DCl-ALA 2008/42. Aseguramiento de la Calidad: políticas públicas y gestión universitaria. (2011, junio). Primeros resultados de la evaluación de impacto. Ponencia presentada en el VI Seminario Internacional acreditación de la calidad de la Educación Superior. RIACES. San José, Costa Rica.

Proyecto Alfa Nro. DCl-ALA 2008/42. Aseguramiento de la Calidad: políticas públicas y gestión universitaria. (2011, setiembre). Impacto de los procesos de aseguramiento de la calidad (AC) a partir de información provista por actores relevantes. Presentado en el Seminario latinoamericano de difusión del Proyecto ALFA, Buenos Aires, Argentina. 
Proyecto Alfa Nro. DCl-ALA 2008/42. Aseguramiento de la Calidad: políticas públicas y gestión universitaria. (s.f.) Dimensiones de calidad. Chile.

Sistema Nacional de Acreditación de la Educación Superior - SINAES. (2009). Manual de acreditación oficial de carreras de grado del Sistema Nacional de Acreditación de la Educación Superior. San José, Costa Rica: SINAES. 